$$
\text { أ. د. د. هلال ادريس الحيالي }
$$

و أ.م.د. طه يونس وياسمين الحيالي

$$
\begin{aligned}
& \text { التنمية البشرية المستدامة والحكم الصالح } \\
& \text { أ. د. هلال ادريس الحيالي }
\end{aligned}
$$$$
\text { مستخلص البحث }
$$

مر مفهوم التنمية بتطورات عديدة وقد اهتم ذكر اقتصاد التنميـة الرأسمـالي بكيفيـة زيـادة الـدخل

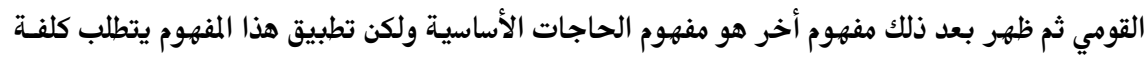

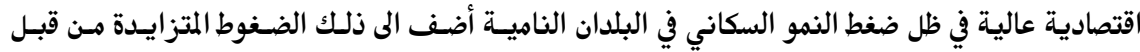

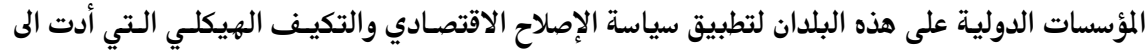

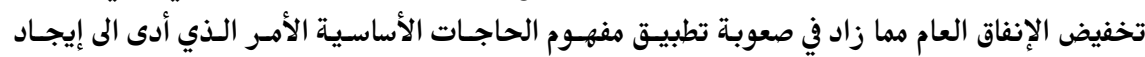
مفهوم جديد للتنمية يهتم بالموارد الاقتصادية والمحافظة على البيئة.

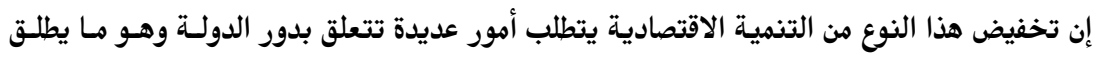

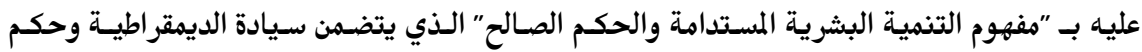

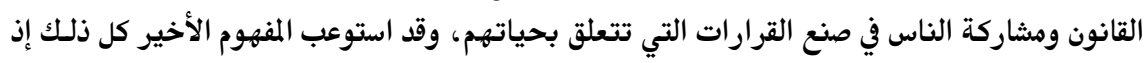

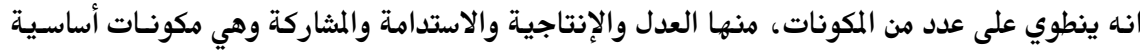
للتنمية المستدامة.

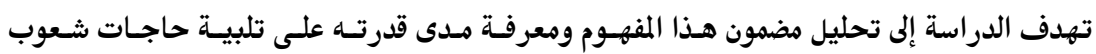

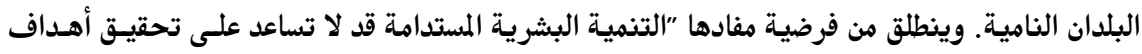

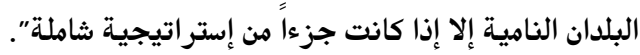

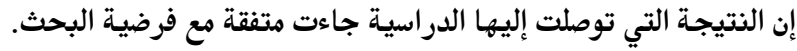


لر الفكر الاقتصادي التنموي بتحولات كبيرة أفضت الى سوق مفاهيم جديدة محاولة منسه

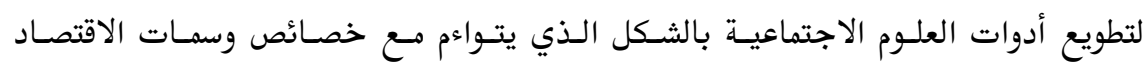

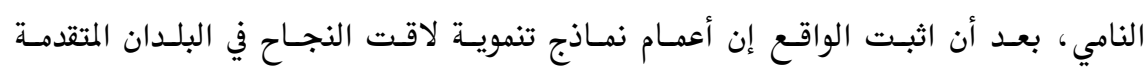

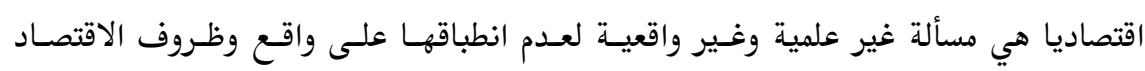

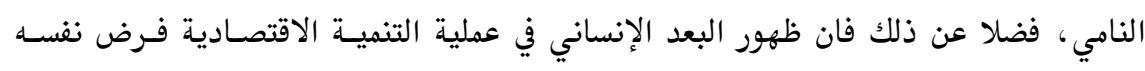

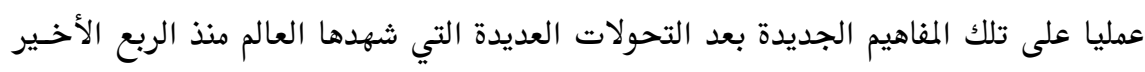
من القرن الماضي. لقد اهتم فكر اقتصاد التنمية الرأسمالي والى حد قريب بكيفيـة توليـد الزيسادة في الـدخل

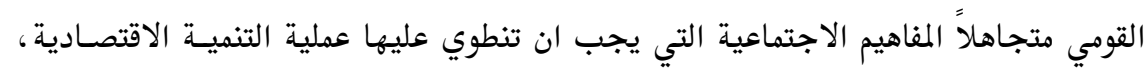

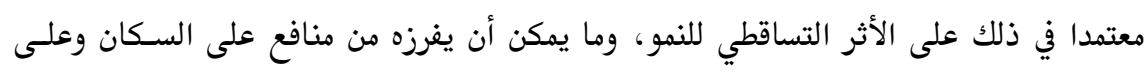

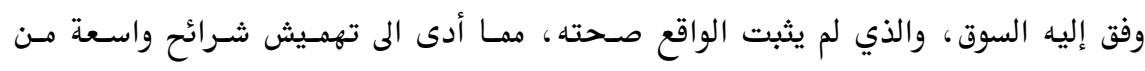

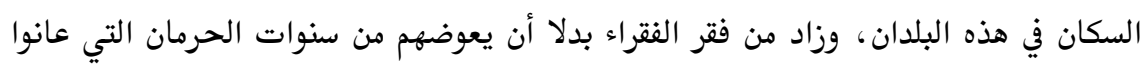

في السبعينات من القـرن الماضسي شـهد العـالم ولادة مـنهج التنميـة الـذي عـرف بمـنهج

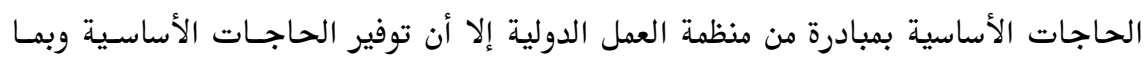

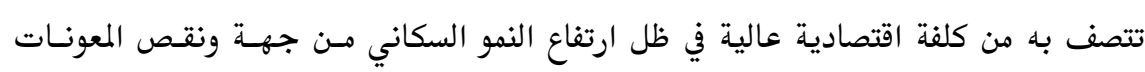

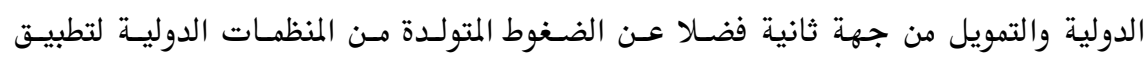

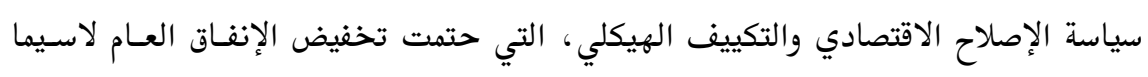

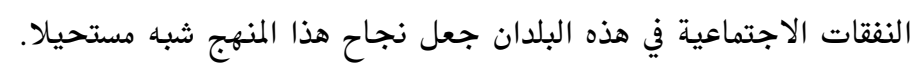

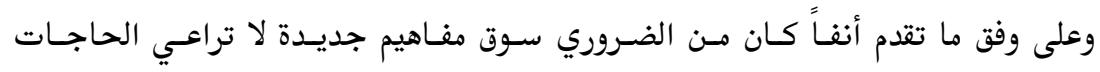

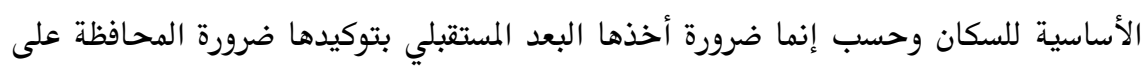

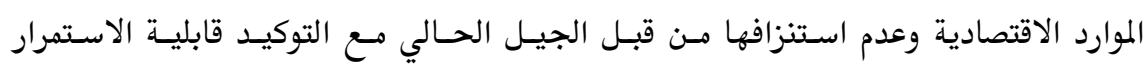




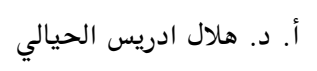

و أ.م.د. طه يونس وياسمين الحيالي

كما وكان من الضروري لهذه المفاهيم إن تستوعب البعد البيئي (الايكولوجي) عـن طريسق

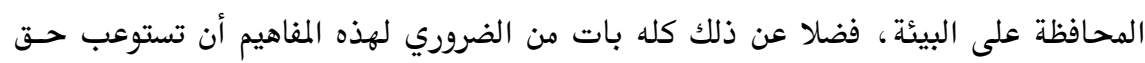

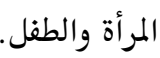

إن تحقيق هذا النوع من التنمية يتطلب جملة اشـتراطات تتعلـق بطبيعـة ودور الدولــة في

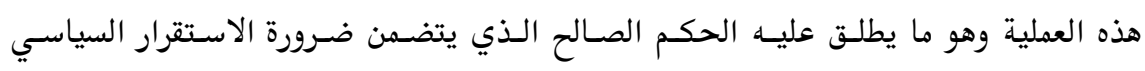

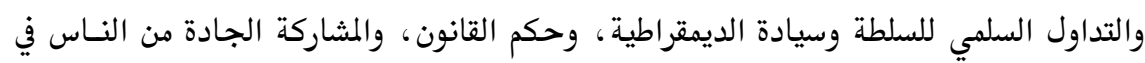
صنع وتنفيذ القرارات المتعلقة بحياتهم. لقد تم استيعاب ذلك كله في مفهوم التنمية البشرية المستدامة الذي تضمن أربـع مكونسات

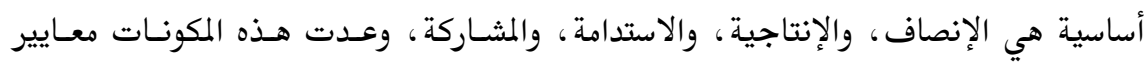

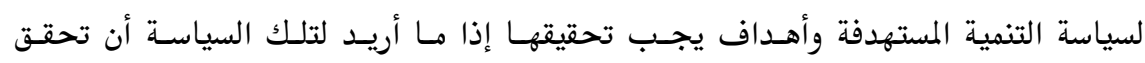

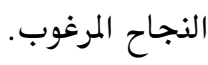

\section{أهمية البحث}

تكمن أهمية البحث في كون النموذجات التي سوقت التنمية الاقتصادية للبلدان النامية لم

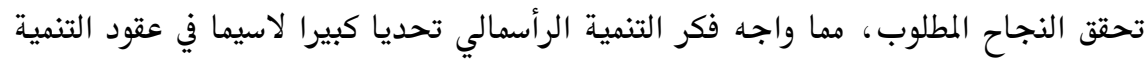

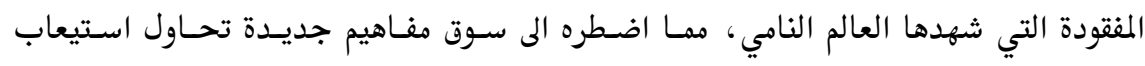

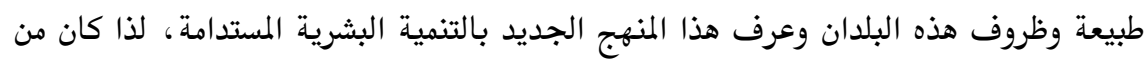
الضروري التعرف على ماهية واشتراطات هذا المسار الجديد. هدف البحث يهـدف البحث الى التعرف على واقع التنمية البشرية المستدامة ومدى قـدرة هـذا المفهوم الجديد على تلبية حاجات شعوب البلدان النامية. 
يفترض البحث على الرغم من أهمية هذه المفاهيم الجديـدة (التنميسة البشـرية المستدامة)

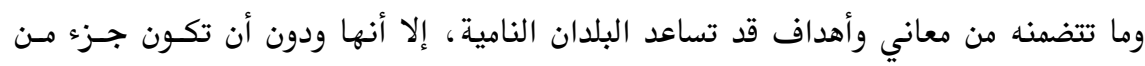
ستراتيجية تنمية شاهلة، غير قادرة على تحقيق الأهداف المتوخاة منها.

\section{أولا: التنمية البشرية المستدامة}

أثير مفهوم التنمية البشرية المستدامة بعد سلسلة مسن التطـورات المفاهيميـة بـدأت عنـدما سوق الاقتصادي فيشر Fisher مفهوم رأس المال البشري في كتابه الموسوم "طبيعة رأس المال

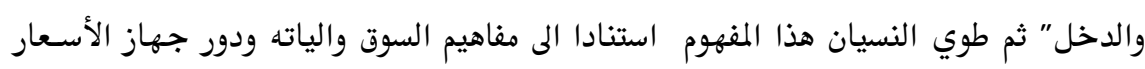

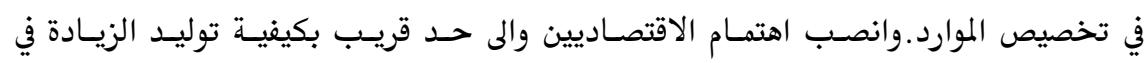

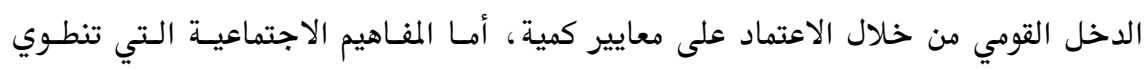

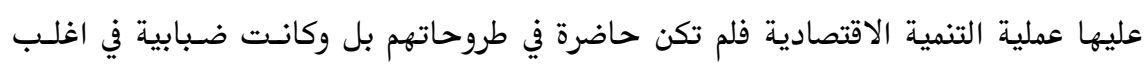

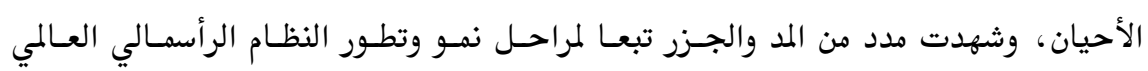

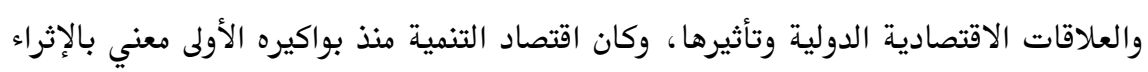

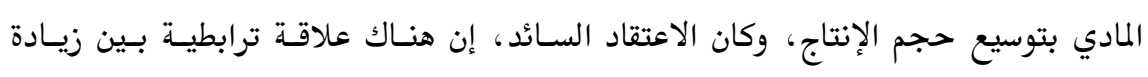

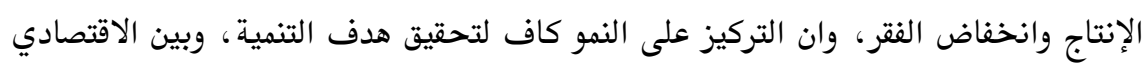

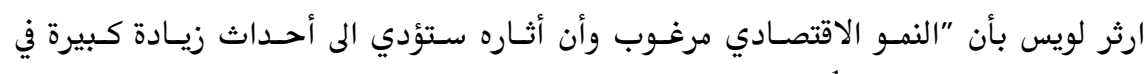

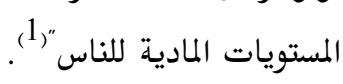
وقد مر فكر التنمية الرأسمالي بتحولات كبيره أفضت الى ظهـور مفـاهيم خاصـة في النهـو

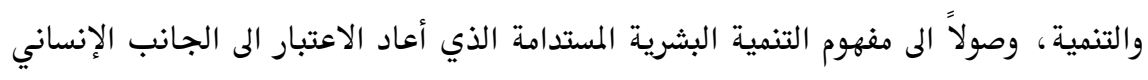

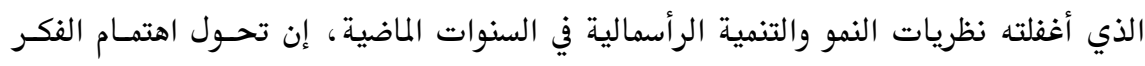

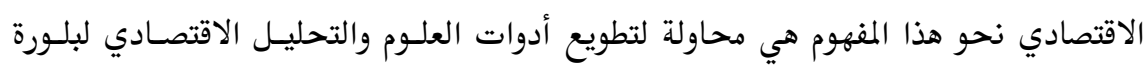

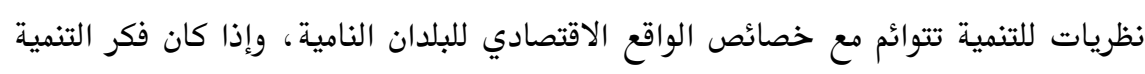

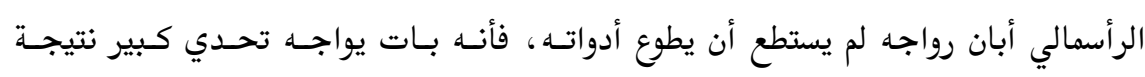

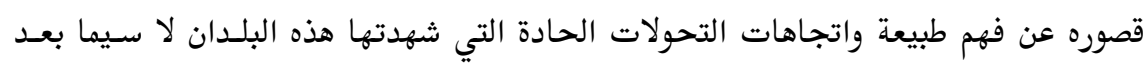

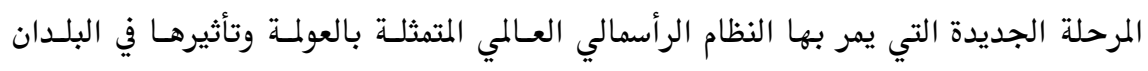


أ. د. هلال ادريس الحيالي

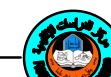

التنمية البشرية المستدامة والحكم...

و أ.م.د. طه يونس وياسمين الحيالي

النامية في ظل فشل نماذج تنمويسة مستنسخة لا تنطبـق مـع واقع مخــالف لبيئسة نشـوئها،

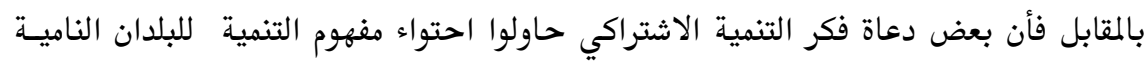

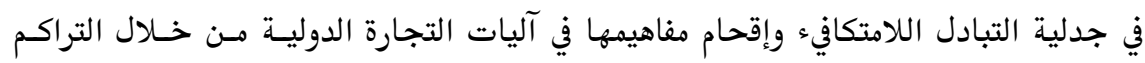

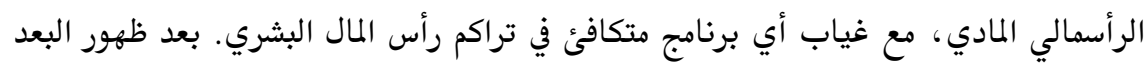

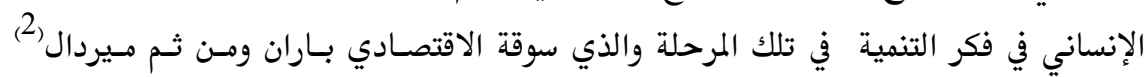
تمد ولادة جديدة لهذه المفاهيم وانتقل الاهتمام من عملية النمو الاقتصادي والأثر التساقطي لتصني

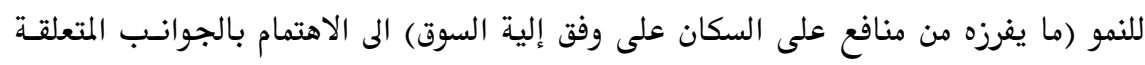

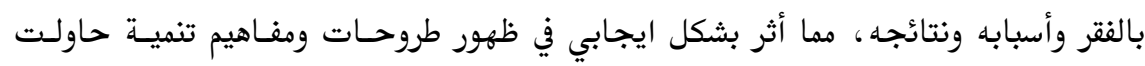

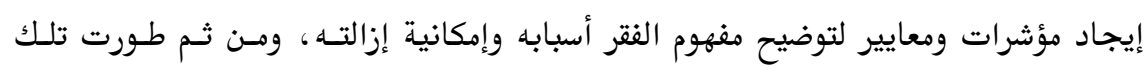

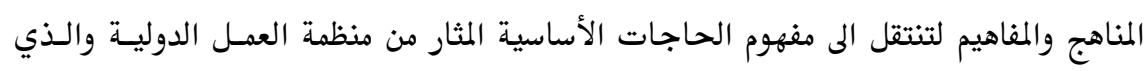

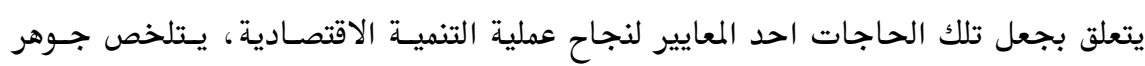

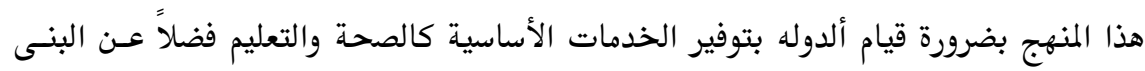

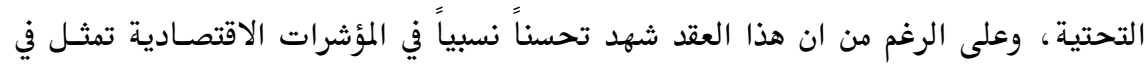

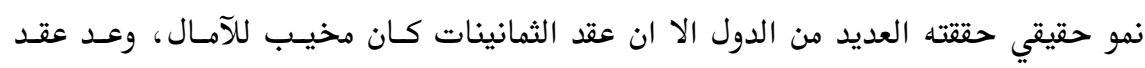

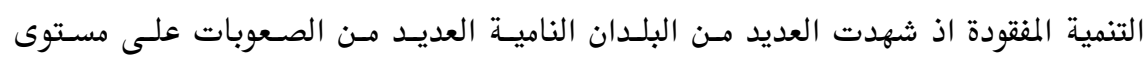

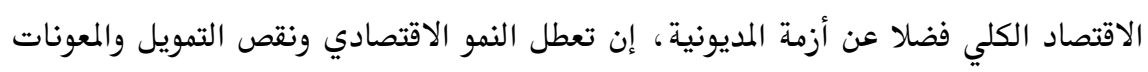

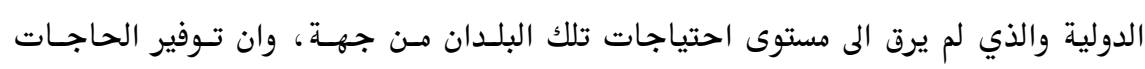

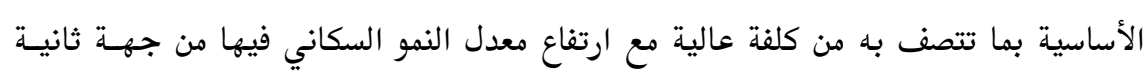
جعلت إمكانية تحقيق هذا المنهج شبه مستحيلا.

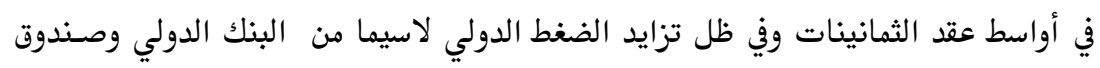

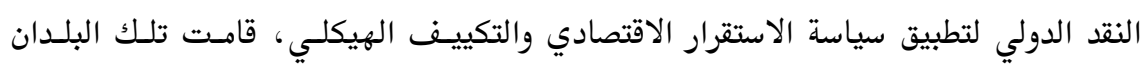

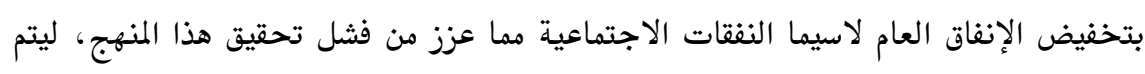

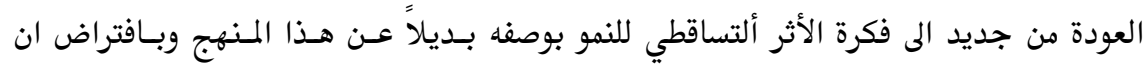

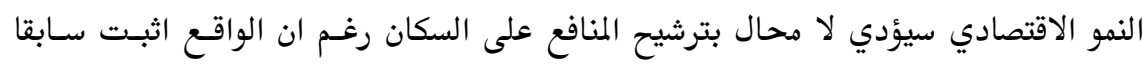

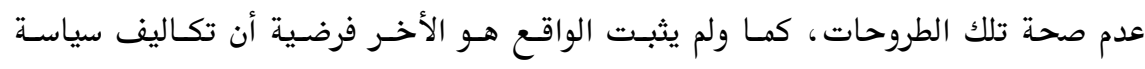


التكييف الهيكلي والخسائر الاجتماعيـة الناجمـة عنهـا تعـد نتـائج عرضـية مؤقتـة وقصيرة

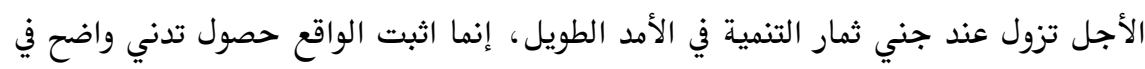

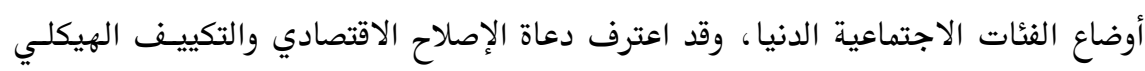

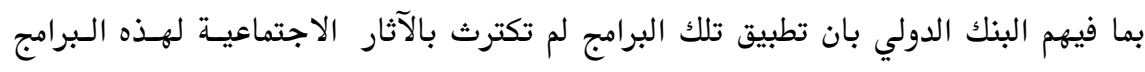
على الفقراء.

إن هذا الواقع حتم تقديم طروحات جديدة تمثلت في ظهور مفهوم التنميـة البشـية ومسن التهن

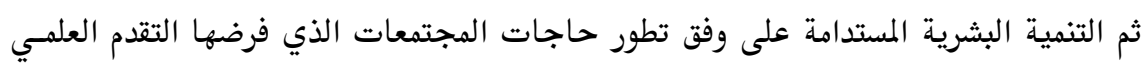

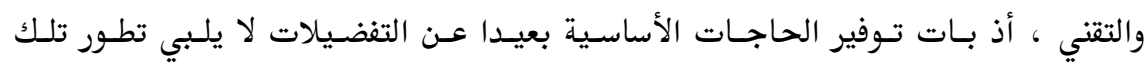

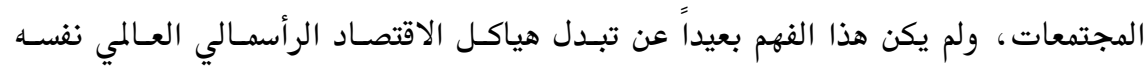

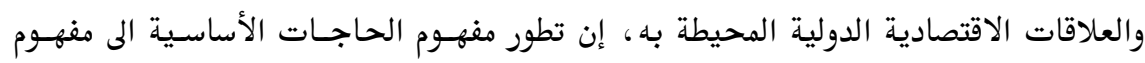

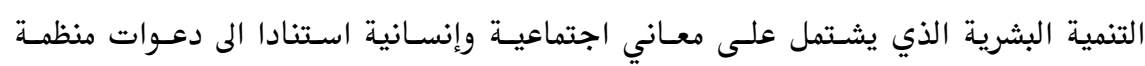

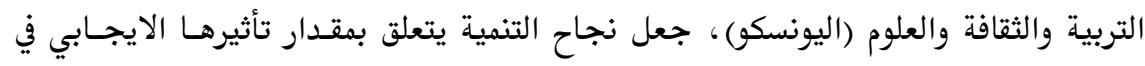

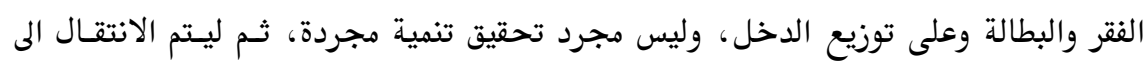

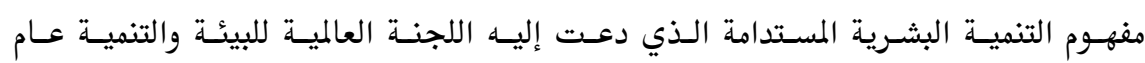

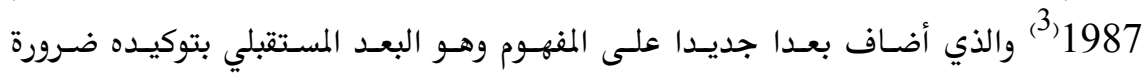

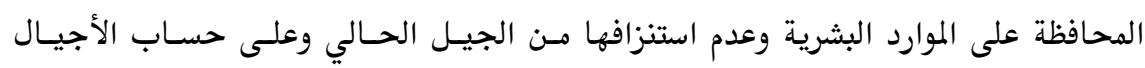

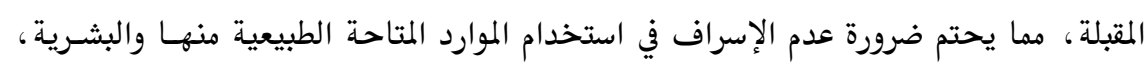

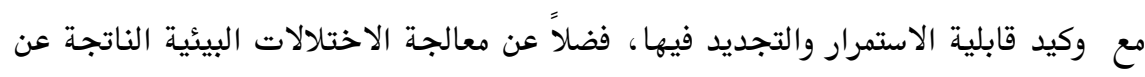
تغير البنى الصناعية للبلدان الرأسمالية المتقدمة وإعادة توزيعها جغرافياً.

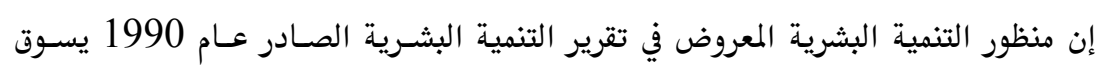

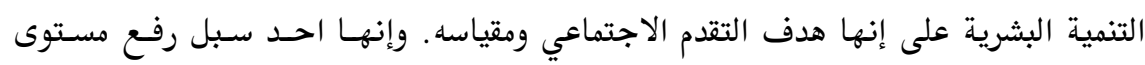

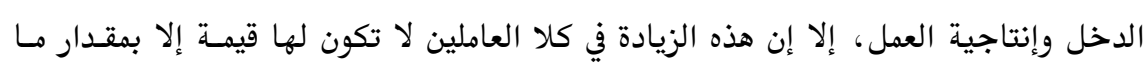
تسهم به في نمو رفاهية الناس.

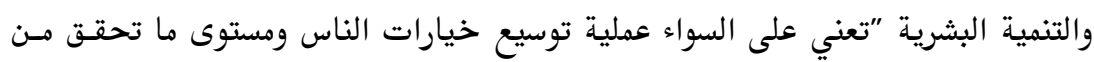

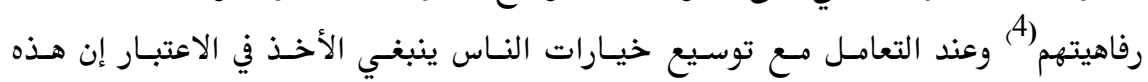




$$
\text { أ. د. هلال ادريس الحيالي }
$$

و أ.م.د. طه يونس وياسمين الحيالي

الخيارات، في واقع الحال، تشمل طيفاً واسعا من القضايا التي تهم النـاس وان هـذا الطيـف يتغير تبعاً للتطور.

إن هذا المفهوم يثير ثلاثة إبعاد تظل أساسية على مستويات التنمية كافـة : حيـاة طويلـة

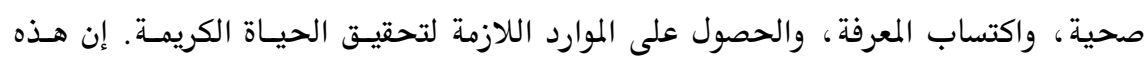

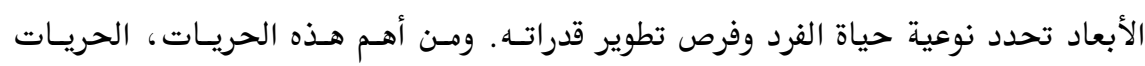
السياسية والاقتصادية والاجتماعية.

إن عملية التنمية البشرية، من وجهه النظر المثارة هنا، قادرة على تحقيق جملة أهـداف

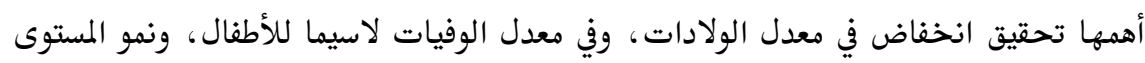

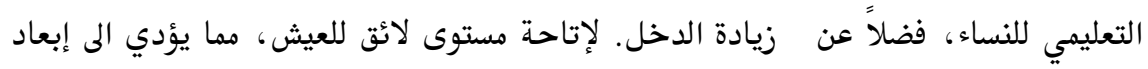
شبح الفقر.

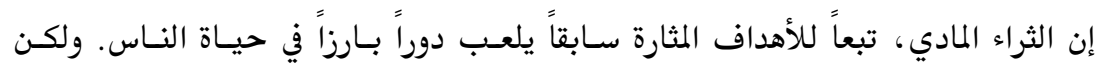

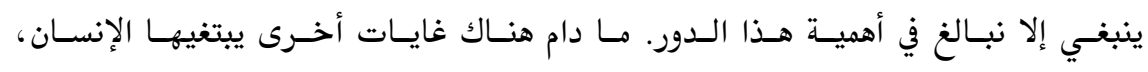

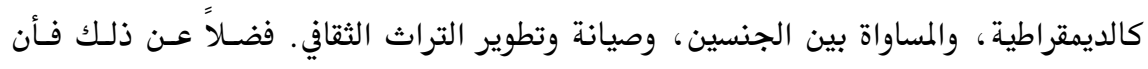

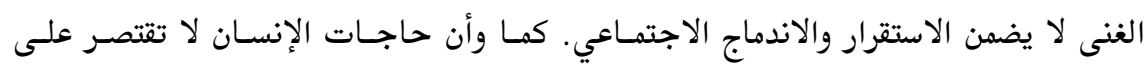

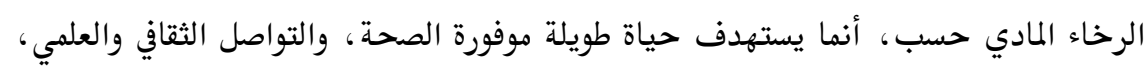

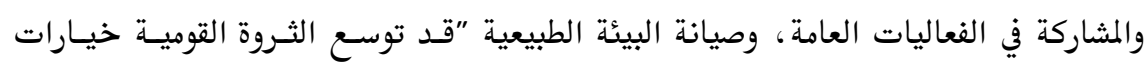

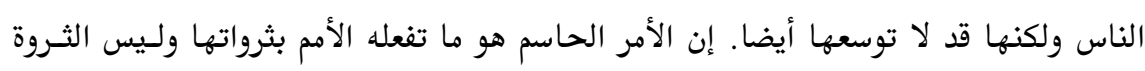

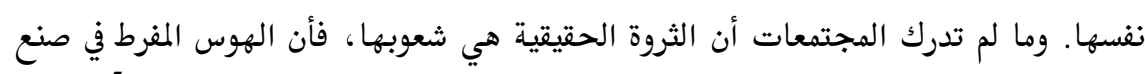

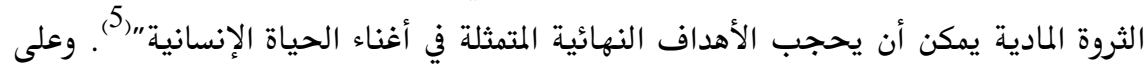
وفق ما تقدم أنفاً فأن مستوى الدخل الذي تحققه دولة ما اليوم قد لا يضمن ازدهاراً اقتصادياً في المستقبل. إن الصفة الأساسية لمنظور التنمية البشرية هي "لا يحتاج الناس الى دخول هائلة لتحقيق

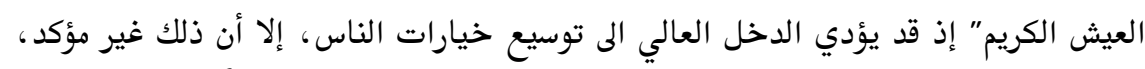

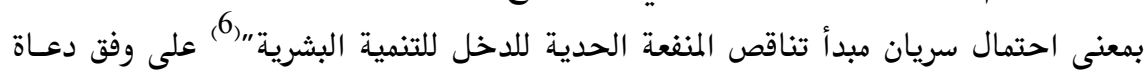
المدرسة الحدية. 


\section{ثانيا: التنمية المستدامة والعوامل البيئية}

إن جهل الجوانب الاجتماعية والبيئية للتنمية، ورسوخ قوالب فكرية تنطوي على إضفاء

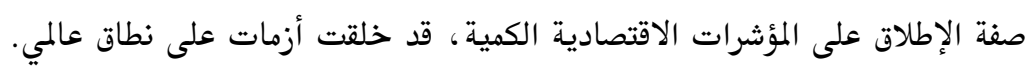

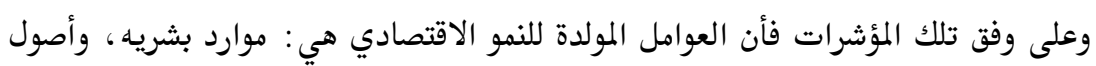

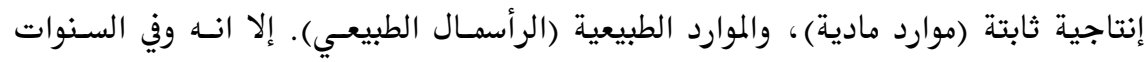

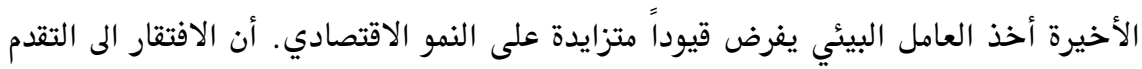

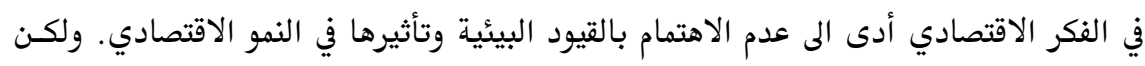

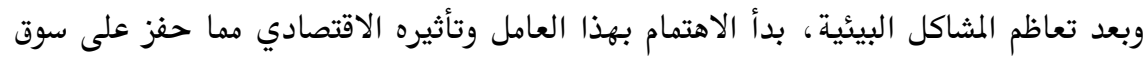
مفاهيم جديدة للنمو.

يعد التطور البيئسي-الاقتصـادي "تقـني المنشـأ" مـادام التقدم الـتقني كثيــ الاسـتخدام

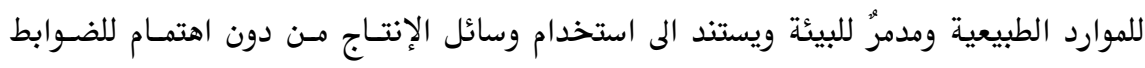
البيئيسة. ولاسـتنزاف المـوارد الطبيعيـة غـير المتجـددة، والاسـتخدام غـير العقلانسي للهـوارد

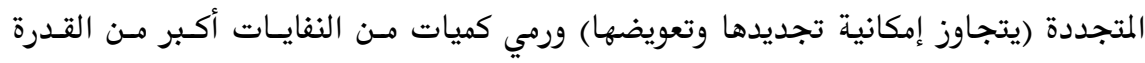
الاستيعابية للبيئة. كل ذلك أدى الى جملة إضرار من مثل تدهور صحة الإنسان واستتنزاف المـوارد الطبيعيـة وتلوث البيئة. فضلاً عن ارتفاع حاد بالتكاليف الاجتماعية للإنتاج.

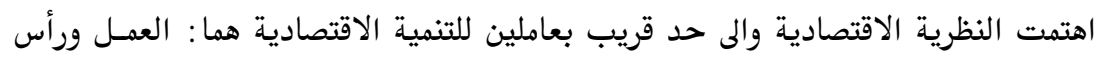

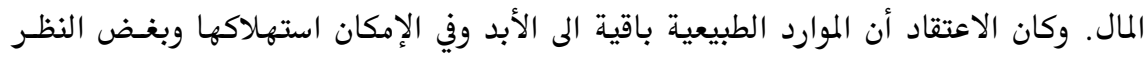

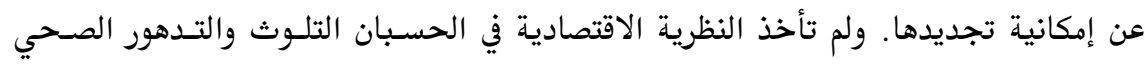

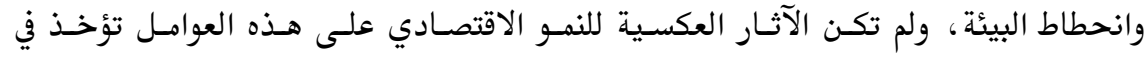

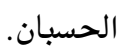
لم يكن هذا التأثير للنمو الاقتصادي مثار تذمر إلا في الربع الأخير من القرن الماضي. وهذه

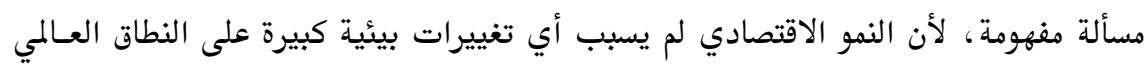




$$
\text { أ. د. هلال ادريس الحيالي }
$$

و أ.م.د. طه يونس وياسمين الحيالي

نظراً للمستوى المتدني نسبياً للقوى الإنتاجية. منذ ذلك الوقت بـدأ العـالم يعسي الحاجـة الى

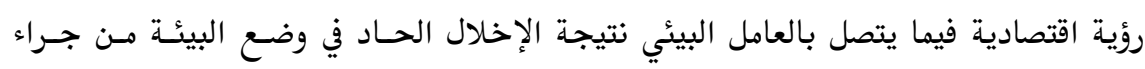

$$
\text { تنامي القوى الإنتاجية وتزايد السكان. }
$$

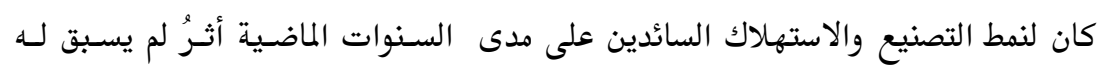
مثيل على البيئة : كاستهلاك الوقود غير العقلاني واستهلاك الماء الصافي، وانبعاث غاز ثاني مداني

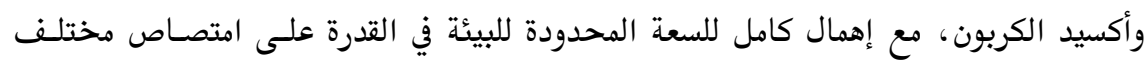

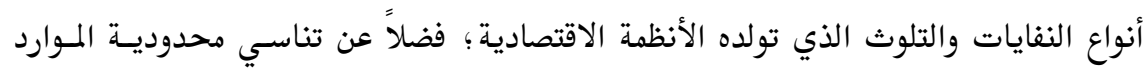

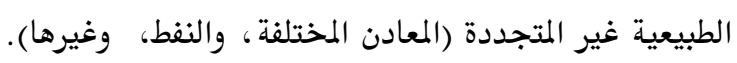

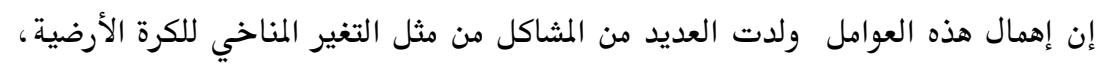

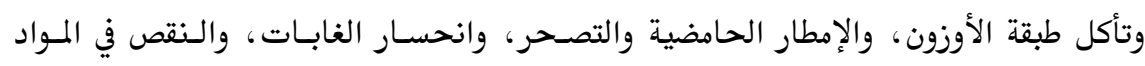

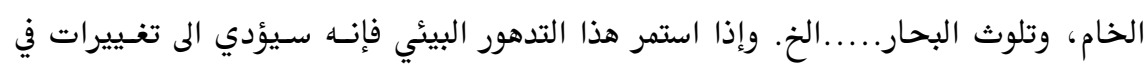
البيئة ينتج عنها عواقب لا يمكن التكهن بها. التها.

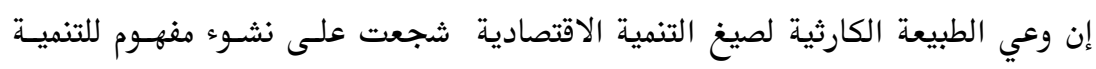

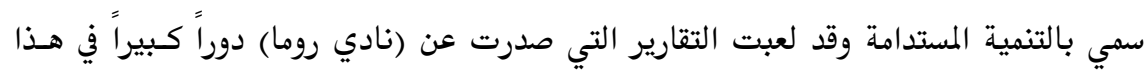
المجال، وأسهمت في ولادة مفاهيم التنمية البشرية والمستدامة.

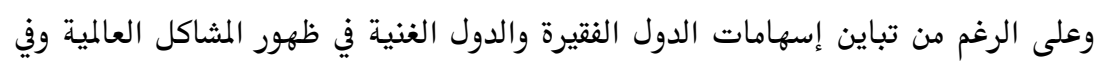

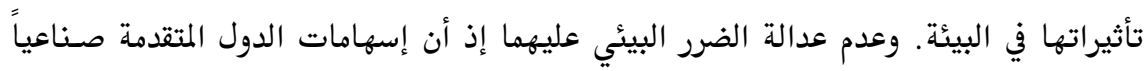

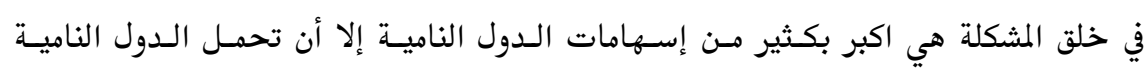

$$
\text { التبعات البيئية السلبية أكثر من غيرها. }
$$

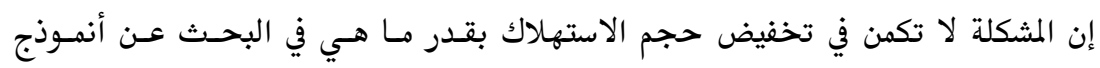

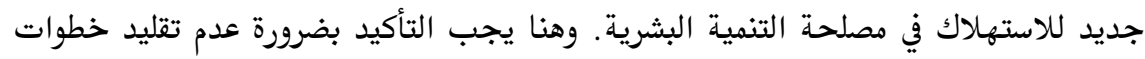

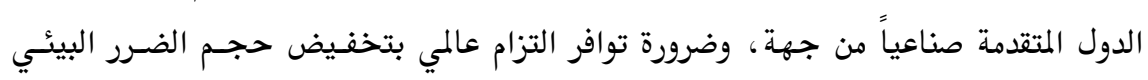

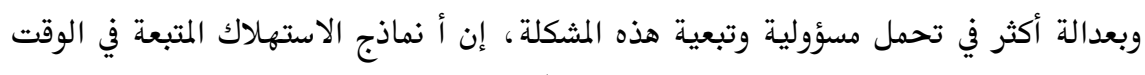

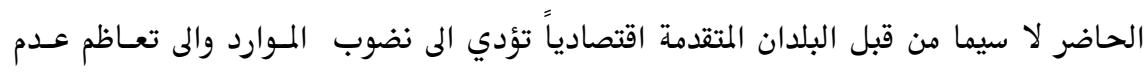
المساواة في تحمل الأعباء والنتائج. 
إن الانموذجات الاقتصادية والاستهلاكية المتبعة في الدول المتقدهـة صـناعياً قـد أضحت

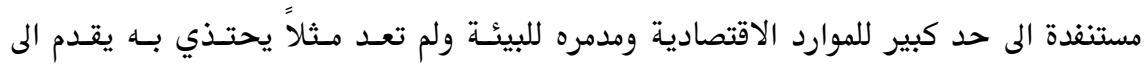

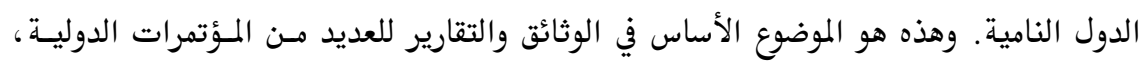

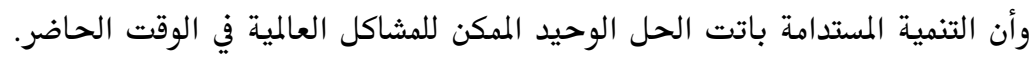

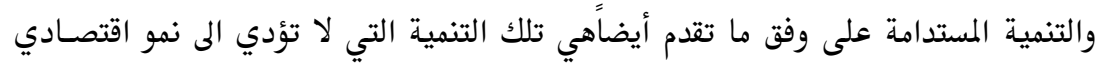

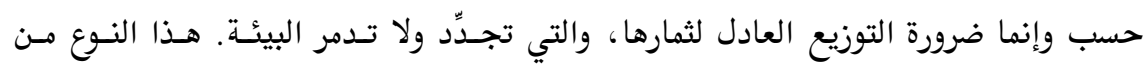

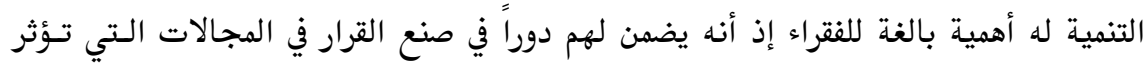

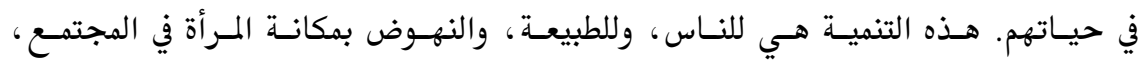

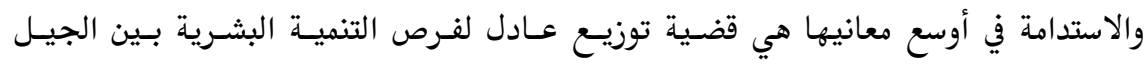

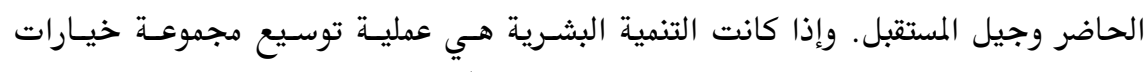
الناس فأن الاستدامة هي تنمية الشخص وقدراته ، رجلاً كان أم امرأة. يتضمن مفهوم التنمية المستدامة الآتي (7):

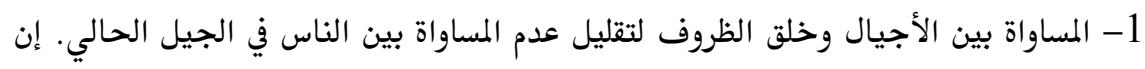

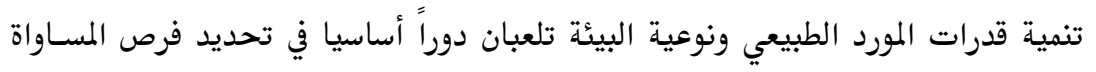

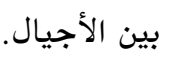

2- يمكن أن يكون العامل البيئي فاعلاً في تحسين حيـاة النـاس، وان عـدم تـوافر الصـحة

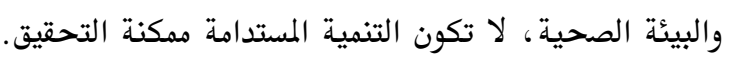

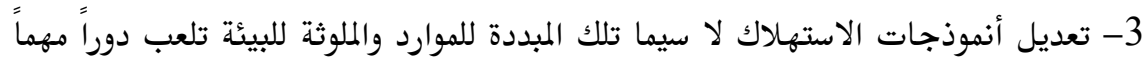
في التنمية البشرية والمستدامة. 4- توكيد حق المرأة والطفل. 


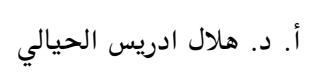

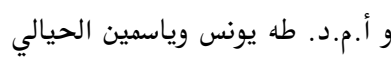

\section{ثالثا: التنمية البشرية المستدامة والحكم الصالح}

إن العلاقات المترابطة بين التنمية البشرية ودور الدولة تتمحور حول كون بناء القدرات

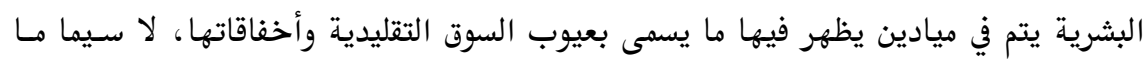

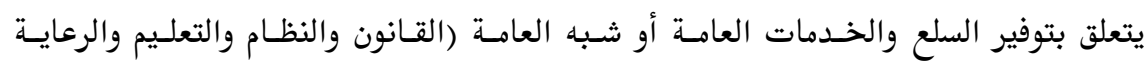
الصحية) والعوامل الاجتماعية والبيئية والسياسية)، فضلاً عن وجود أسواق ناقصة واندات وانعـدام

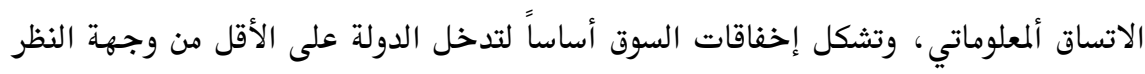

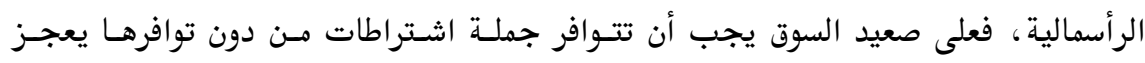

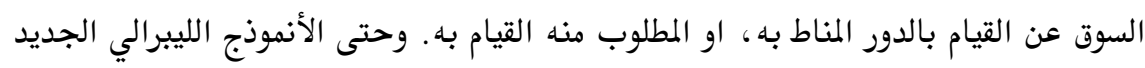

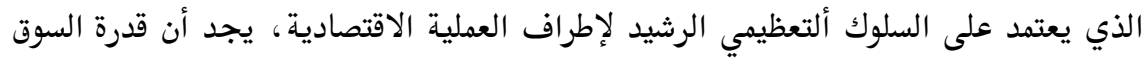

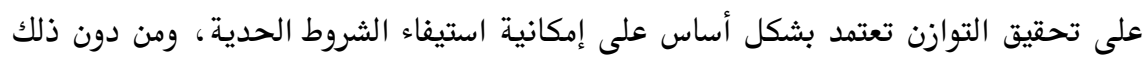

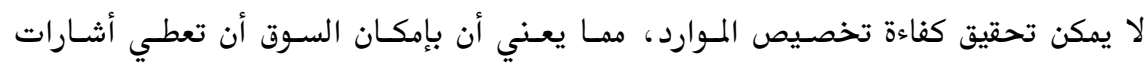

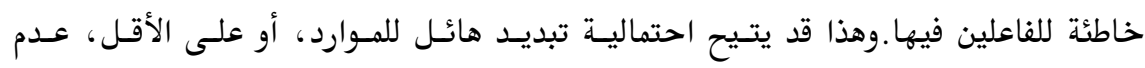
أمكانية تقديم الخدمات بالقدر الكافي. وعلى وفق ذلك، من غير المحتم عمل اقتصاد السوق بالكفاءة المطلوبة ما لم تتوافر الشروط بلإئ

$$
\text { 1- عدم وجود نواقص في السوق تحد من آلياته (كمال السوق). }
$$

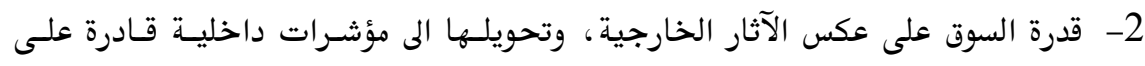

$$
\text { عكس التكاليف والمنافع الاجتماعية في أسعار السوق. }
$$


3- شفافية السوق، مع تكافؤ الفرص لجميـع المتعـاملين بهـا في الحصـول على المعلومـات وأتاحتها بأدنى كلفة ممكنة. 4- - حرية انتقال وحركة عوامل الإنتاج جغرافيا وقطاعيا.

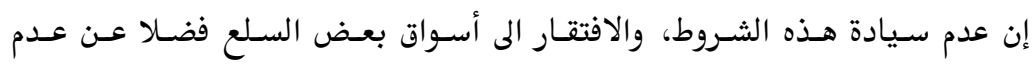
التعويض عن بعض التكاليف والمنافع المترتبة لإطراف العلاقة في السوق، وعدم تضمينهم ثمن ما يسببونه من

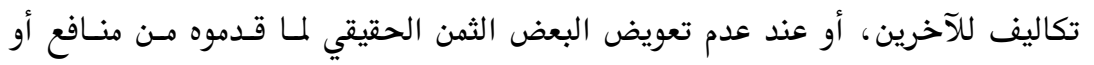

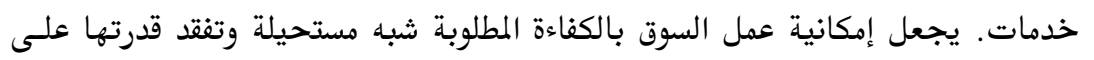

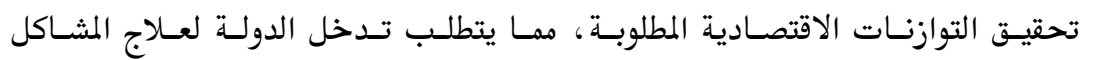
الآتية : -

1- علاج ظاهرة فشل أو عدم كمال السوق لاسيما ظهور منشآت احتكاريسة تحسد الكميـات

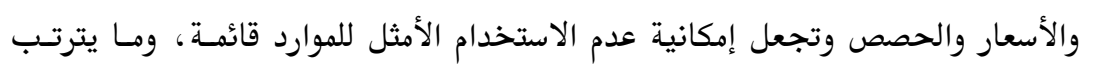
عليه من الافتقار الى التخصيص الأمثل للموارد.

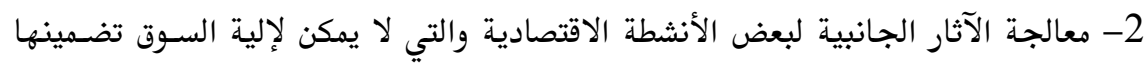
او عكسها في أسعار السوق للسلع المتولدة عن هذه الأنشطة ( تلوث البيئة مثلا).

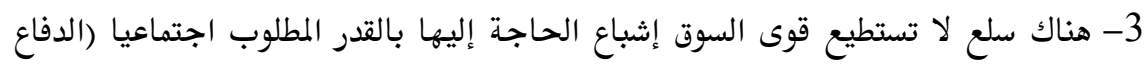
والأمن). 4- تعرض السوق للتقلبات الاقتصادية الدورية، مما يصاحبها مشاكل عدم الاستقرار، والتي تتطلب تدخل الدولة (البطالة، التضخم، النمو غير المستقر).

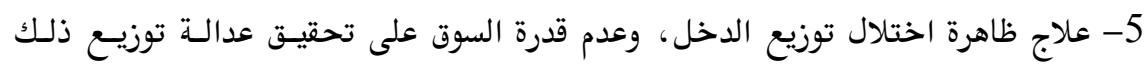

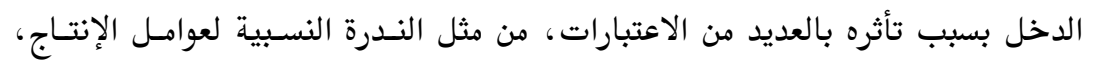

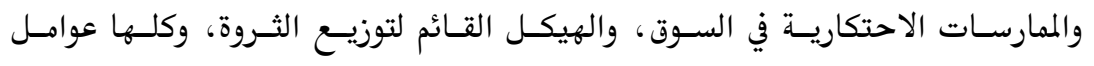

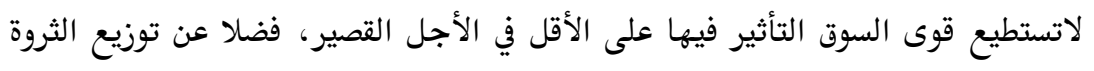
والتنمية إقليميا وجغرافياً وقطاعياً. 
أ. د. هلال ادريس الحيالي

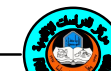

و أ.م.د. طه يونس وياسمين الحيالي

6- معالجة عدم قدرة السوق على إتاحة المعلومات بطريقة متماثلة لجميـع الإطـراف العاملــة

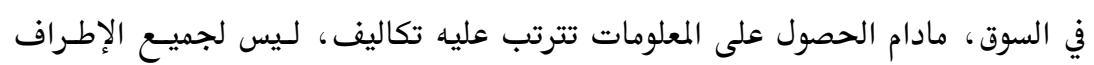

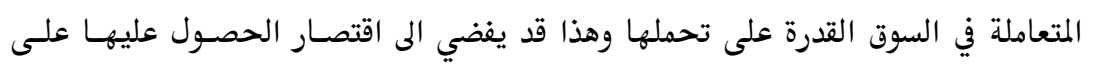
الفئات القادرة على الدفع ومن ثم سوء تخصيص الموارد ما لم تتدخل الدولة.

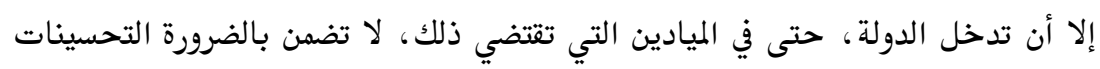

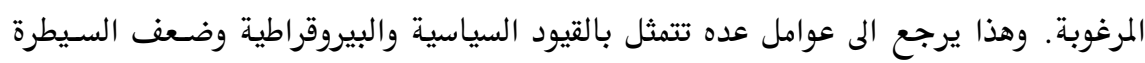

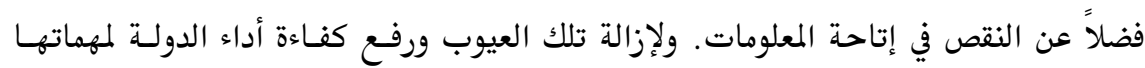

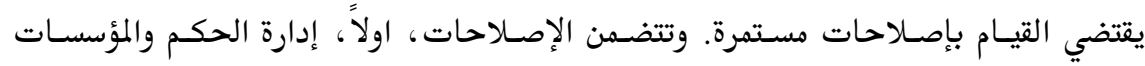

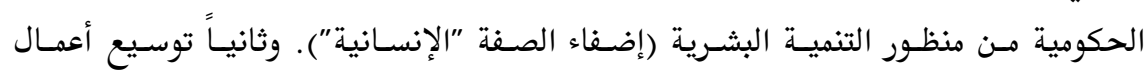

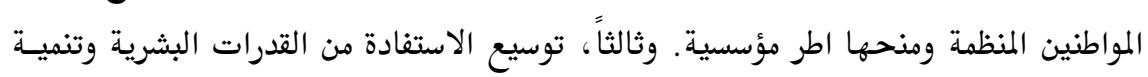

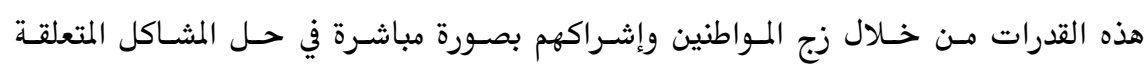
بحياتهم (تمكينهم). تستطيع الدولة ومؤسساتها تحقيـق الارتقـاء بالتنميـة البشـرية، إلا أنسه وفي حالـة كـون

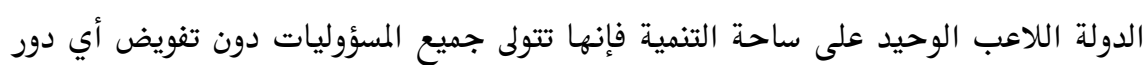

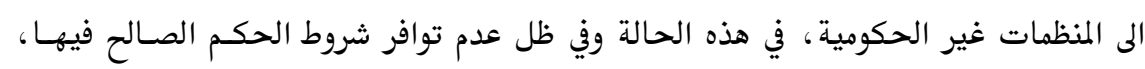

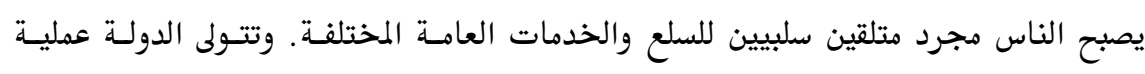

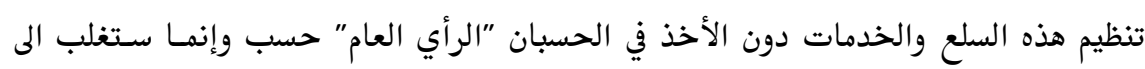
حد كبير مصالحها الطبقية ومصالح البيروقراطية المستشرية فيها.

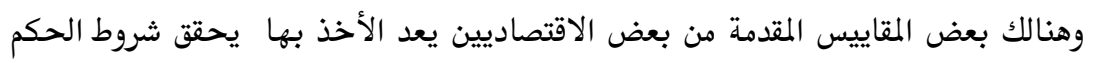

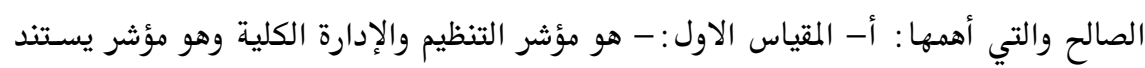
الى متوسط مجموعة من المعايير الآتية(8):

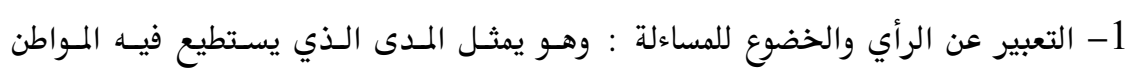

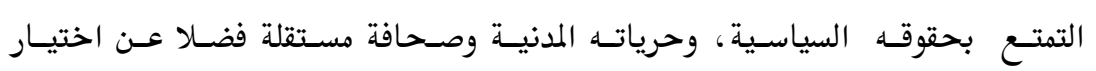
حكومته،والتي يمكن التعبير عنها بجملة واحدة هي مدى توافر الحريات الديمقراطية. 
2- الاستقرار السياسي وغياب العنف وعدم احتمال الإطاحة بالحكومة بوسائل غير دستورية او يمكن ان تعبر عنها بالتداول السلمي للسلطة على وفق المعائير المعائ الديمقراطية.

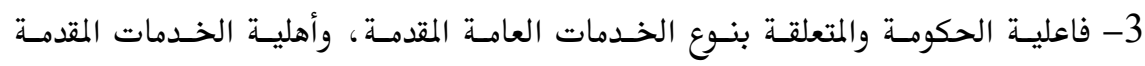

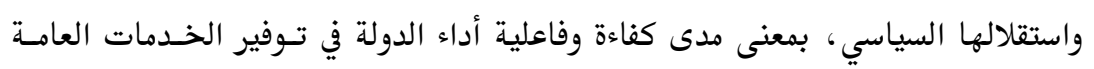
بعيدا عن الاعتبارات السياسية، او اعتبارات ذاتية تعبر عن مصالح فئوية محددة.

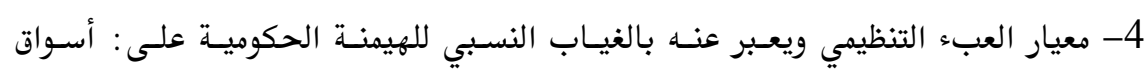

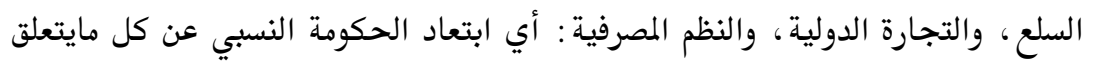
بالضوابط الحاكمة في الاقتصاد المستندة الى فكر الليبرالية الجديدة. 5- معيار حكم القانون ويهتم هذا المعيــار بحمايـة الأشـخاص والملكيـة، وكفــاءة واستقلال القضاء، وتنفيذ العقود. 6- معيار التحرر من الابتزاز ، وهو يهتم بعدم استغلال السلطة العامة او المنصب السياسي والإداري لتحقيق مكاسب خاصة. وعامة فإن هذه المعايير تتعلق بمدى شيوع الديمقراطية ومؤسساتها الفاعلة وبمسدى كفـاءة

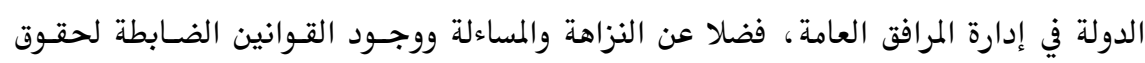

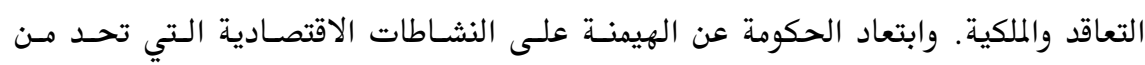
الحرية الاقتصادية.

المقياس الثاني: يركز هذا المقياس بصورة حصرية على حقوق الملكيـة وهـدى الحمايـة الـتي تتلقاها الملكية الخاصة. وأخيرا: المقياس الثالث الذي يتعلق بمدى وجود قيود قانونيسة ودستورية على السـلطة التنفيذية والرؤساء والزعماء السياسيين.

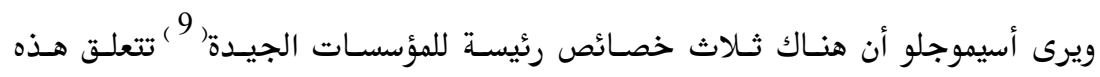

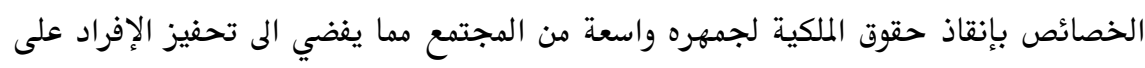
الاستثمار والمشاركة في الحياة الاقتصادية، ووجود قيود قانونية ودستورية على لئى إعمال النخبة

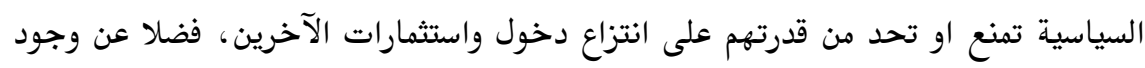




$$
\text { أ. د. هلال ادريس الحيالي }
$$

و أ.م.د. طه يونس وياسمين الحيالي

درجة من تكافؤ الفرص فيما يخص قطاعات المجتمع المختلفـة تسمح بمشـاركة الجميـع في

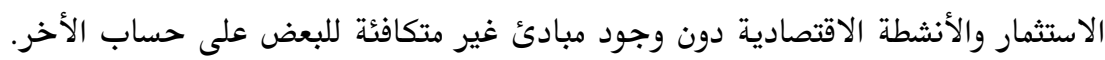

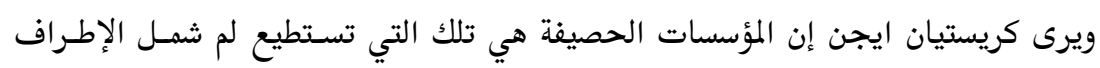

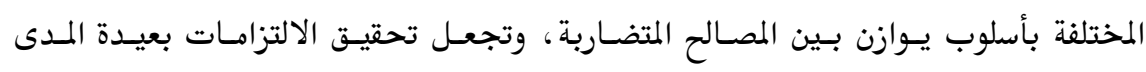

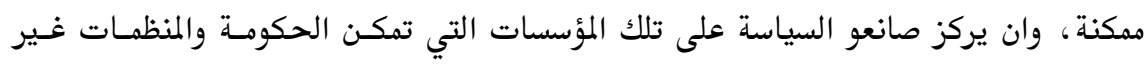

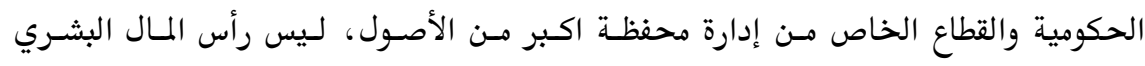

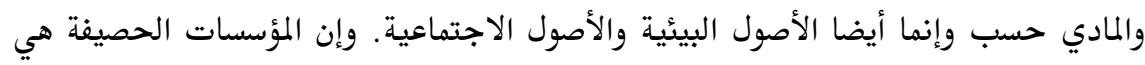

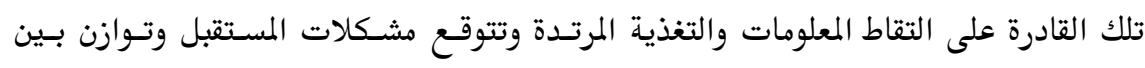

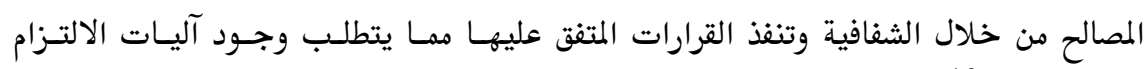

$$
\text { وتنفيذ العقود (10). }
$$

إن المهمة الرئيسة في سياسة التنمية البشرية وعلى وفق المعطيات السابقة تتمثل في تطوير نظام إداري كفء خاضـع للمحاسبة، فضـلا عـن تـوافر إجـراءات وآليـات تحقيسق الفائسدة القصوى من تصرفات الدولة الاتفاقية.

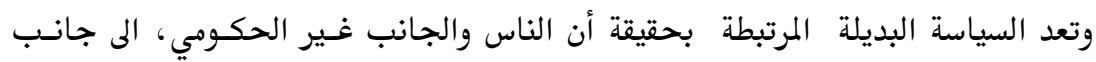
مؤسسات الدولة، يجب أن يشاركوا في النهوض بالمسؤوليات (تطوير وتنفيذ تلك البرامج).

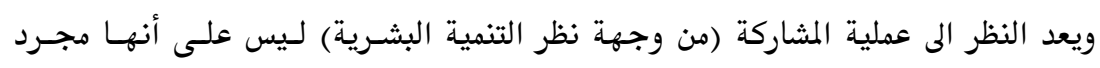

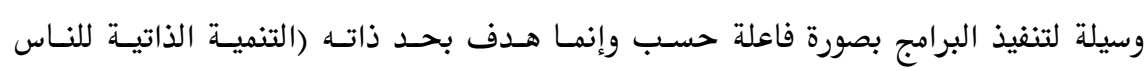

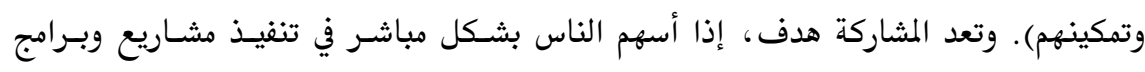
التنمية بشكل كفء. تنطوي المشاركة على تمكين الناس، أي، تفويض السلطات الى الناس واكتسابهم للمعرفة

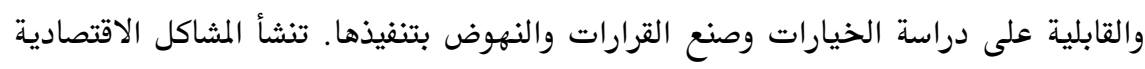

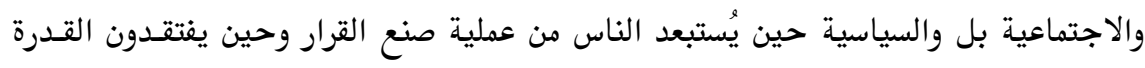

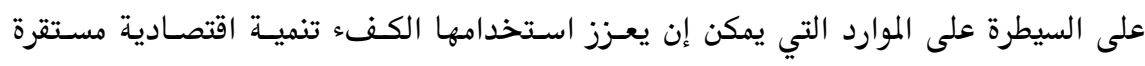
ولصالح الناس أنفسهم. 


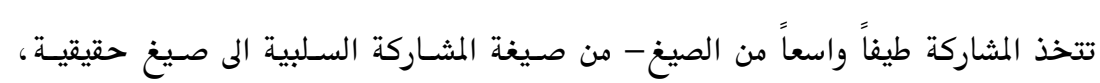
وتعد المشاركة المقترنة بالمحاسبة والمسؤولية الجماعية الصيغة الأكثر فاعليسة مـن المشـاركة.

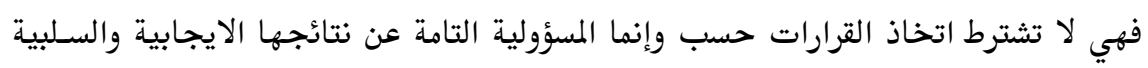
والعمل على تحقيق الغايات والأهداف المشتركة.

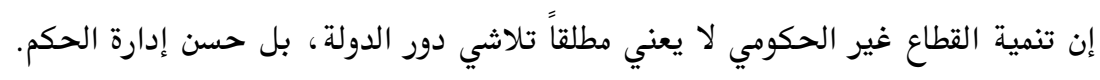

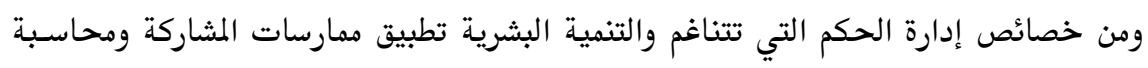
البيروقراطية والانفتاح للجههور.

الخاتمة

استطاع فكر اقتصاد التنمية الرأسمالي أن يطور العديد من المفاهيم الجديدة والتي أفضـت التـا

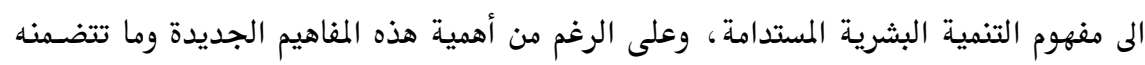

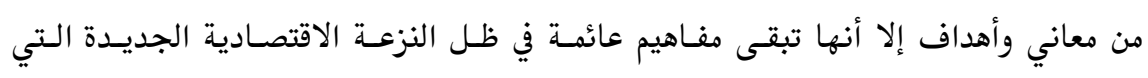

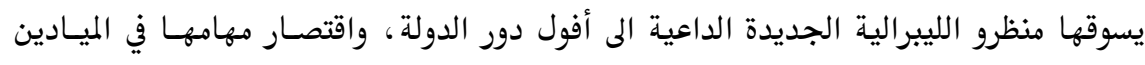

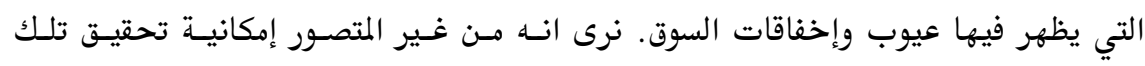

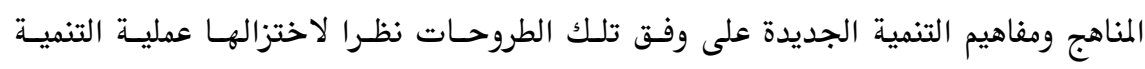

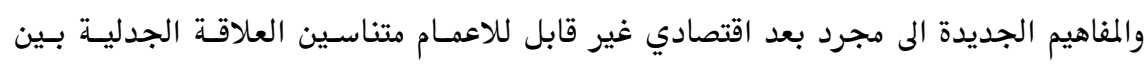

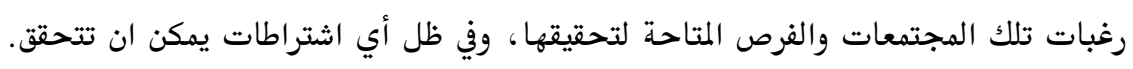

$$
\text { يتضمن مفهوما التنمية المستدامة : }
$$

1- المساواة بين الأجيال وخلق الظروف لتقليل عدم المساواة بين النـاس في الجيـل الحسالي.

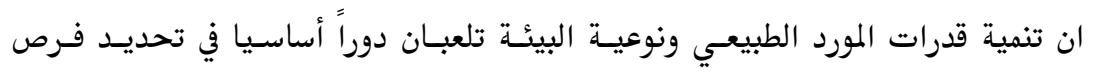

$$
\text { المساواة بين الأجيال }
$$

2- يمكن أن يكسون العامـل البيئي فـاعلاً في تحسـين حيـاة النـاس، وان الصحة والبيئسة الصحية، بدونهما لا تكون التنمية المستدامة مهكنتي التحقيق.

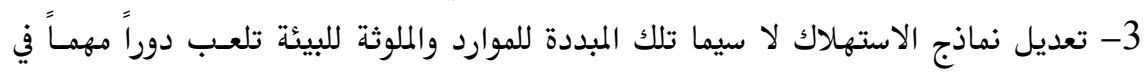
التنمية البشرية والمستدامة. 
أ. د. هلال ادريس الحيالي

و أ.م.د. طه يونس وياسمين الحيالي

4- التأكيد على حق المرأة والطفل. إن تحقيق هذا النوع من التنمية يتطلب جملة اشـتراطات تتعلـق بطبيعـة ودور ألدولـه في

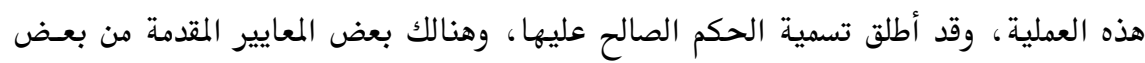

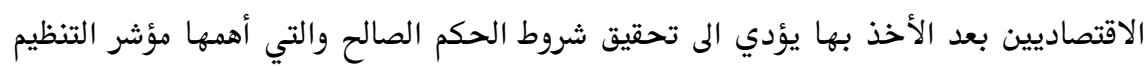
والإدارة الكلية وهو مؤشر يستند الى متوسط مجموعة من المعايير الآتية:

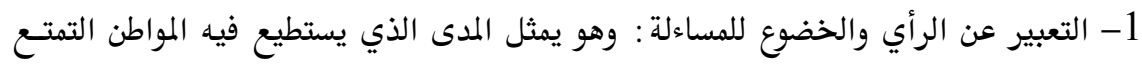
بحقوقه السياسية، وحرياته المدنية وصحافة مستقلة فضلا عن اختيار حكومته ، والتي لتي يمكن التعبير عنها بجملة واحدة هي مدى توافر الحريات الديمقراطية.

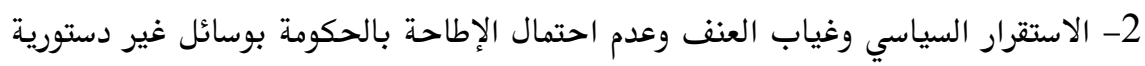
او يمكن ان تعبر عنها بالتداول السلمي للسلطة وفق المعايير الديمقراطية.

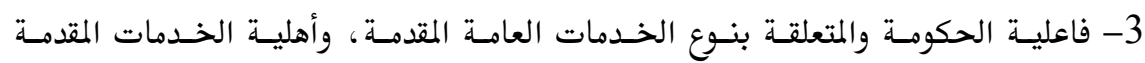
واستقلالها السياسي، بمعنى مدى كفاءة وفاعلية أداء الدولة في توفير الخـدمات العامـة بعيدا عـن الاعتبارات السياسية، او اعتبارات ذاتية تعبر عن مصالح فئوية محددة.

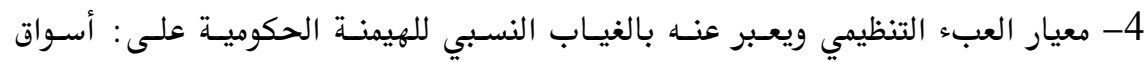

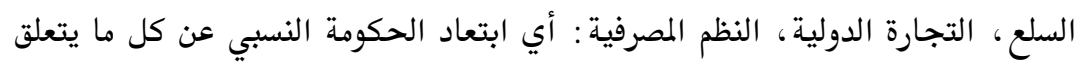
بالضوابط الحاكمة في الاقتصاد المستندة الى فكر الليبرالية الجديدة.

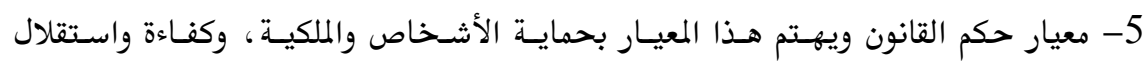
القضاء، وتنفيذ العقود. 6- معيار التحرر من الابتزاز، وهو يهتم بعدم استغلال السلطة العامسة او المنصسب السياسي العيد والإداري لتحقيق مكاسب خاصة.

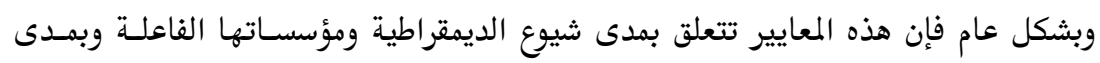

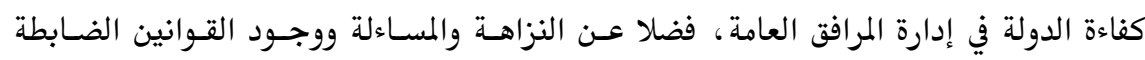

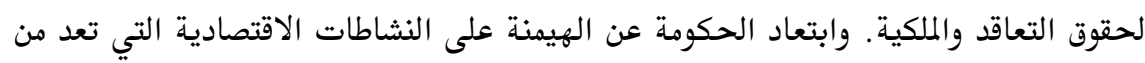

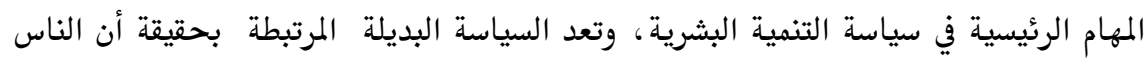

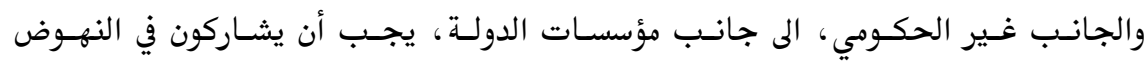


بالمسؤوليات، مما يعني ضرورة المشاركة، يعـد النظـر الى عمليـة المشـاركة (مـن وجهـة نظر

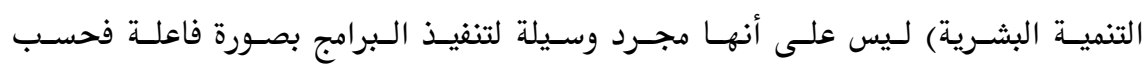

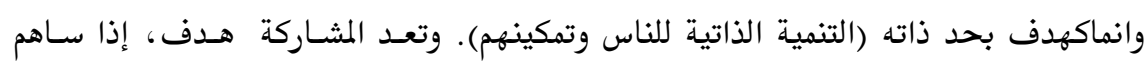
الناس بشكل مباشر في تنفيذ مشاريع وبرامج التنمية المطروحة بشكل أكنأ.

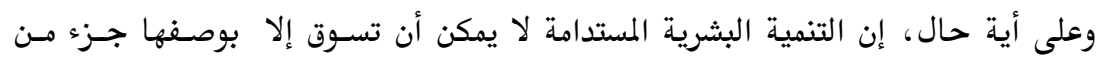

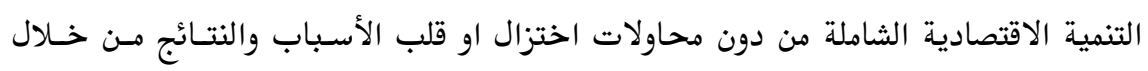

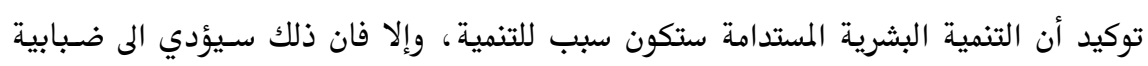

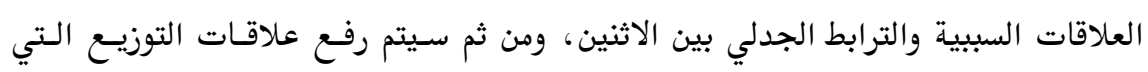

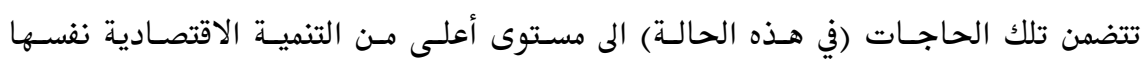

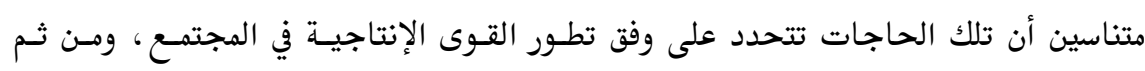

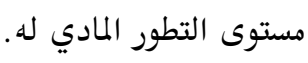

\title{
The Sustainable Human Development and the Rational Governance
}

\begin{abstract}
The economic development concept passed in many developments and the capitalism economic development ideology was concerned in how to generate the increasing of national income. After that another
\end{abstract}




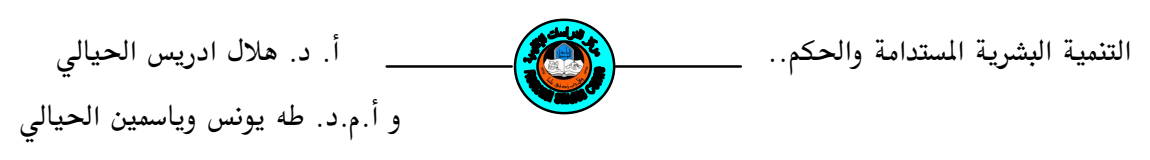

concept appeared which is the basic needs concept, but the application of this concept requires high economic cost under the pressure of population growth in the developing countries, add to that the increasing pressure by international institutions on these countries to apply the economic reforms policy and structural adjustment which led to reduce the public expenditure that increased the difficulty of application of the basic needs concept, the matter which led to find a new concept for development interested in economic resources and preserving the environment.

The attainment of this kind of economic development requires many things that concern the state role that is named "The sustainable human development concept and rational governance" which include the prevalence of democracy, law governance and the people contribution in making decisions which concerns their life. The last concept included all that because it contains a number of constituents such as equity, productivity, sustainability, and contribution and these are basic constituents for sustainable development.

This study aims to explain the implication of this concept and to know its ability to meet the needs of the developing countries. This concept springs from a hypothesis saying "that the sustainable human development might not help to achieve the goals of developing countries unless it was part of comprehensive strategy".

The result which reached through this study came to be consistent with the researcher's hypothesis.

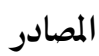

(1) Lewis: The Theory Of Economic Growth 1955. P 431.

(2) A:Baran, Paul: The Political Economy of Growth, monthly Review press, New York, 1957.

(3) B:.Myrdal ,Gannar:Asian Drama,An Inquiry into the Poverty of

Nations (3 rols) pelican Books London, 1968. p.123. 
(3) اللجنة العالمية للبيئة والتنمية: مستقبلنا المثـترك، ترجمسة محمـد كامـل عـارف، مراجعسة علسي

حسين حجاج، سلسلة عالم المعرفة، المجلس الوطني للثقافة والفنون والاداب، الكويت، مجدئ، 1989.

(4) United Nations: Development Programming.

(5) (UNDP, 1990:10

(6) (UND, 1994a: 15).

(7) أ.د. هلال ادريس مجيد: رسم سياسات التنمية البشـرية بنـاءاً على حاجـات المجتمـع، ص 11،

مؤتمر جامعة الزيتونة، تونس 2005.

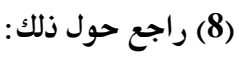

أ- داني روديك دار فيند سويرا مانيـان: أسـبقية المؤسسـات (مـاذا تعـني ومـاذا لاتعـني)، مجلـة

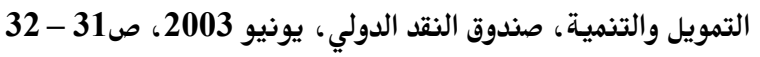

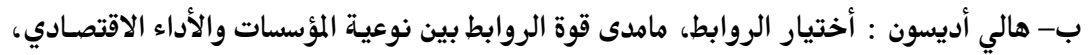

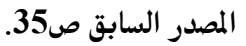

(9) دارون اسيموجلو: الأسباب الجذرية، نهج تـاريخي لتقيسيم دور المؤسسـات في التنميسة الاقتصادية

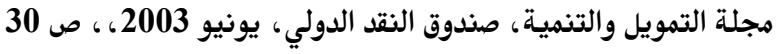

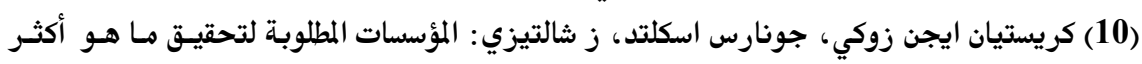

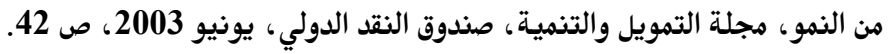

